\title{
Why copyright matters in music
}

This chapter first addresses the question of why copyright matters in music and why it is so important for any musician, any artist or any other person working in the music industry to care about copyright. Once we are all on the same page (pun intended) with the 'why', we can get into the 'what' - in Chapter 2, which provides an introduction to what exactly copyright is.

\subsection{Why copyright matters in music}

Having worked with many artists and musicians, I know that the first step in this conversation is to highlight why you should even care about copyright at all. Some musicians and artists believe that copyright is either something for someone else to be concerned with, or something that is just plain boring. Others perceive copyright as too complicated or as an obstacle to their creativity, and avoid it for those reasons. These are just some of the common misconceptions that give copyright a bad reputation. This chapter addresses these concerns, clarifies what copyright is for and how it can benefit you, and explains how just a little understanding of copyright can go a long way to help you avoid making unnecessary mistakes.

So, without further ado, here are my reasons to let go of any of the aforementioned misconceptions and carry on reading this book about copyright in the music industry. 


\subsection{Copyright is for creators}

Copyright is not a natural phenomenon; it is human made - which is great, because this means that in places where it is not working, it can be changed! In fact, it has to change all the time, to keep up to date with new technologies and consumption behaviours in society. The law is not fixed or static; it is a constant work in progress. There are certainly copyright rules which do not work and need updating, but that does not necessarily mean that the entire idea of copyright is broken. It is useful to think of copyright as a concept, or big idea, that was invented to enable and support the creation and distribution of creative works. The concept of copyright is then written into law - these are simply the rules, or you could say policy, which are decided on by the government or judiciary to determine how the big idea of the copyright game will be played on their field, or in their country. The rules are different in different countries, because each has their own entire legal system, culture and way of doing things. There are international agreements signed between many countries that set minimum standards as to what the rules should say, but beyond that the specifics of the rules are tailor made. These rules can and should - be changed and updated from time to time. This section will talk more about the idea and concept of copyright. The specific rules are explained in further detail in the subsequent chapters.

The main point here is that humans made copyright - and did you ever wonder why? Not to make your life more difficult, but for the benefit of creators, creativity and the spread of culture and knowledge.

Copyright regulation as we know it came about after the printing press was invented in the fifteenth and sixteenth centuries - essentially because, before printing, manual copying was pretty laborious and so not such a threat to writers. The first copyright law was created in the UK in 1709 and was called 'An Act for the Encouragement of Learning, by Vesting the Copies of Printed Books in the Authors or Purchasers of such Copies, during the Times therein mentioned'. Seriously. But at least it was self-explanatory; the law was made to encourage learning by granting copyright to authors. It does this by giving the author the exclusive right over their work, which enables them to licence it, disseminate it and receive remuneration in return, which then enables them to continue to create. Copyright has come a long way since then, and the rules are different, but the principal purpose is the same. Copyright helps musi- 
cians protect their creativity, get paid for their work and control the use of their music. It also enables the production of the work to be published and shared. In that sense, copyright is a win-win. Society gets music and musicians get remunerated for their creativity.

There are a number of different ways to justify why we have copyright. Not everyone agrees on which is the most suitable and, as explained below, different countries tend to lean towards one or the other. Regardless of which you find the most compelling, they all clearly emphasise that copyright is for creativity and, therefore, for the creator. Knowing why we have copyright can help to understand why it is useful for you. There are two main rationales for why we have copyright: the Anglo-American economic approach and the Continental Europe author perspective. The two justifications are briefly explained below.

Broadly speaking, the Anglo-American approach emphasises the economic role of copyright as a system that compensates creators for their work, which would otherwise be a freely accessible commodity with no market value, because it is easy to duplicate. So, copyright steps in to ensure that creators get paid for their work, which enables them to continue to create, and rightsholders can disseminate that creativity, knowledge and culture - thus benefiting society as a whole. The economic justifications of copyright focus on different elements of this transaction. For example, some argue that copyright is granted because it is fair to reward the creator for their efforts and for giving it to the public, making copyright a form of legal gratitude. Another related perspective is that the sharing of creativity and innovation is good for society as a whole, and therefore copyright acts as an incentive for creators. This perspective presupposes that without copyright creators would not be motivated, or able, to create and disseminate their work.

A different perspective, often taken in Continental Europe and referred to as personality or author rights, argues that when you create something it is an extension of yourself and your personality, and therefore you should own and control it. This justification takes the view that copyright is granted because it is the right thing to do, not because society will benefit from the work. Under this umbrella of author rights, there are also a number of different justifications for copyright that focus on a slightly different emphasis. Some believe that copyright is a way for the author to ensure that no one speaks in their name without their authority; for 
example, copyright allows you to stop an organisation that you do not support from using your song in their advertising campaign.

At the heart of copyright and all these justifications and different rationales is the motivation to protect the creation and dissemination of creative works, balanced with the public interest. The take-home message here is that copyright is meant to help creativity, not hinder it!

\subsection{Copyright is how music makes money}

The music business is fundamentally a copyright industry, as copyright exploitation is the central mechanism for revenue generation within it. For example, the music industry generated $\$ 43$ billion in revenue in the USA ${ }^{1}$ and contributed more than $£ 5.2$ billion to the UK economy in $2018,{ }^{2}$ through music creators, music retail, recorded music, music representatives, music publishing and live music. All these activities are made possible through the exploitation of music copyright, the musical composition, the recording of the music, music performances and the branding of the artist.

From the economic perspective, as explained above, it could be said that all these ways of making money from music are made possible by the copyright laws that provide the creator with the rights in the music, which are then licensed to allow for its dissemination. Of course, copyright is not the only required factor - the music, business models, people and consumers are also essential elements in the way that the music industry makes money - but copyright does play a fundamental role. Understanding copyright can therefore help to monetise your music from global revenue streams.

In my experience of working with creators and musicians, especially early on in their careers, I have come across somewhat of a trend in response to talking about making money from creative work. There is a romanticised notion of the struggling artist: the idea that a good creator, or a real

\footnotetext{
Citi GPS, Putting the Band Back Together: Remastering the World of Music (Citi GPS: Global Perspectives \& Solutions, August 2018) 3.

2 UK Music, Music by Numbers 2019 (UK Music, 2019) 6.
} 
creator, is focused only on their creativity and is utterly unconcerned with matters of financial success. For some creators with whom I have spoken, it seemed as if talking about copyright and money in relation to their work was an insult to their creativity. They wanted me, and the world, to know that their craft was about creativity and their creative output was about communicating something meaningful to them and had absolutely nothing to do with money or financial gain. Money was a dirty word. If you can relate to this idea of the creator, you may wish to consider the following perspectives.

If you are uncomfortable thinking about making money from your music, try this: consider all the time and energy you put into your work, into learning and perfecting your craft and into creating your music. Think of money as just another form of energy (bear with me), and making money from your creativity therefore as simply a fair exchange. Just as in the reward rationale for copyright explained above, it is legal gratitude for the effort you have put into creating and sharing your work. Another way to look at it, from the incentive perspective, is that copyright enables you to be remunerated for your efforts so that you can take what might otherwise be a hobby and turn it into a career. You are then financially supported to continue to create.

A few years ago, I was part of a project that involved creating a copyright education platform called copyrightuser.org. As part of this project, we interviewed a host of different creators about their thoughts and feelings on copyright, in order to better understand the creators' perspective and inform the material we provided on the website. We filmed the interviews and you can watch the videos on the website. When we interviewed the musicians, one of the questions that we asked them was: 'What motivates you to create?' One of the interviewees replied: 'Money motivates me because DJing isn't a hobby for me, it's my actual career. ${ }^{3}$ If you think about it from a big picture perspective, you are not the only one who benefits from your creativity. You are able to create, and society is able to benefit from your creativity being shared. And copyright facilitates this exchange.

There is another recurring theme that crops up when talking to early career creatives, which you may recognise. It is that at one point or

3 www.copyrightuser.org/create/creators-discuss/musician/ accessed 6 November 2020. 
another someone has told them that they cannot possibly make any money from their music - that this is a pipe dream. Especially in the age of the internet and online infringement, the music industry is different from what it was when CD sales, or cassettes, or vinyl, or the radio held it all together - and so on and so forth with the pessimism.

Of course, it is true that things are different now than in those times. However, please consider that everyone speaks from their own experience. If you asked Elton John or Stormzy or Beyoncé, do you think they would agree that there is no money to be made in music? I didn't think so. All right, so not everyone is going to be as successful as Beyoncé, but you can say that about every industry. The point is that people do make money from music and the music industry continues to thrive. Music is part of who we are. It has been part of humanity since humanity. Musicians and artists have been making money from music for literally hundreds of years. While the way the money is made might shift, business models will adapt to changes in technology and society; it is still possible to make a career in music, and I personally believe that it always will be.

In Western culture, there is a stereotype of the struggling artist; one who lives on low or little income, working irregular hours and willing to suffer this lifestyle for the sake of their art. While there is of course some basis for this preconception in that the majority of artists tend to be on a low income, and do work all hours, this does not mean it is impossible to cultivate enough revenue to make music your career - particularly when you have a working knowledge of copyright in your toolbox! Moreover, as Section 1.4 discusses, copyright is not just about the money; it is also about owning and controlling your work.

\subsection{It's not just about the money}

The question of why we create music itself in the first place is more complex than asking why we have copyright! Research has shown how music can change your mood or help you run faster. Music is used as a therapy technique for people with dementia. Darwin said 'music is our greatest mystery'. It has also been described as an evolutionary adaptation 
that helps us to navigate the world and deal with change. ${ }^{4}$ One of the musicians we interviewed for copyrightuser.org answered the question 'What motivates you to create?' by saying: 'I don't think that you can be solely motivated by money in this industry ... you just have to love what you do, love the music.' In fact, the love of music was a recurring theme in many of the musicians' answers to this question of what motivates them to create.

Love and passion for music, as well as other non-monetary rewards from creating music and working in the music industry, have been demonstrated to be reasons for motivation and job satisfaction in research about musicians. For instance, one research study found that artists have different criteria and conceptualisations of what is considered a good job and a good income. Moreover, in looking at predictors of income and income satisfaction, the study found that artists derive value from their work in a variety of ways in addition to monetary income. In particular, the study identified that artistic activities associated with reputational rewards and altruistic behaviours were also important to the artists' job satisfaction. ${ }^{5}$

In that case, you might think copyright is actually less important if creators are motivated by their love for the music and not the financial incentive. However, we also asked the musicians in the copyright interviews: 'What does copyright mean to you?' In response, they noted that it is 'a way of people knowing who's written the song'. Another theme that came up in the interviews was that copyright was used as a way to control the spread of their music; where, when and how it was used. Most of the artists said that if someone else wanted to use their music, they would want the person to ask for their permission first. Copyright is what allows the musicians to have this control. Having copyright in their music grants them the sole right to copy and use their work, and so if someone else wants to use it they need the permission of the rightsholder first. (Unless they benefit from a copyright exception, explained in Chapter 5.)

Leonid P, 'How Music Helps Resolve Our Deepest Inner Conflicts' (The Conversation, 24 March 2015) https://theconversation.com/how-music-helps-resolve-our-deepest-inner-conflicts-38531 accessed 14 June 2020.

5 Miller A and Cuntz A, Unpacking Predictors of Income and Income Satisfaction for Artists, WIPO Economic Research WIPO Working Paper No. 50 (WIPO, December 2018). 
Copyright, and related rights such as moral rights (discussed in Chapter 4 ), is a way to control the use of your creativity. It allows you to own your work and control how and where it is shared, as well as how it is used or edited. Whether to use the song as it is, or to make a remix of a song, or to use it in an advertising campaign - copyright owners are empowered to make these decisions about their work.

Copyright also enables people to know who created the work, as it recognises the creator and copyright owner. This is significant for the creator and also for the public. It is important for the public to know who created a song because, if they like it, they might want to find other songs by the same artist, for example. This is not to mention our tireless curiosity as humans to discover more and more about an artist, as evidenced in the documentary Searching for Sugar Man. The documentary film tells the story of two superfans from Cape Town who go in search of Rodrigues, an American musician whose music failed to take off in the US but became incredibly popular in South Africa - unbeknown to Rodrigues himself.

Fans and fan communities are another layer to the magic that music creates. They are also another reason why control of where and how your music is used is important. Consumers today, more than ever before, take into consideration broader factors in deciding where their loyalty lies. This is shown, for example, by the case of R. Kelly. Following the sexual assault allegations addressed in the Surviving R. Kelly documentary, there was a \#MuteRKelly protest outside Kelly's studio in Chicago, calling for a boycott of his music. As Laura Gillespie, Ethics Fellow at Stanford University, explains: 'The idea is that in listening to the songs of a person who has failed to respect some value I claim to hold, then perhaps I am failing in some way to respect that value. ${ }^{6}$ Copyright allows you to control the use of your music, and decide if it can be used for and by causes, campaigns and people or organisations that align with your values, and therefore your listeners, fans or followers. For example, you may remember a Nescafé coffee advert in 2003 that featured Muse's cover of the Nina Simone song Feeling Good. Nescafé, owned by Nestlé, did not have permission to use the song, as Muse reportedly did not want their music used in support of this product. The band took legal action to enforce

Jaya S, 'The Ethics of Pressing Play: Navigating Popular Music When Alleged Misconduct Is Seemingly Everywhere' (Billboard, 21 December 2018) www.billboard.com/articles/columns/pop/ 8491160/ethics-of-pressing-play-in-music accessed 14 June 2020. 
their copyright and were paid $£ 500,000$ in a settlement deal, which they donated to the charity Oxfam.

\subsection{You do not need to be a lawyer}

As mentioned at the beginning of this chapter, some of the misconceptions about copyright include things such as 'this isn't for me to worry about, I am the talent' or 'it's too confusing for me'. Granted, some aspects of copyright regulation and policy can be complicated, but the good news is that you do not need to be a legal expert - that is what lawyers are for. So, to some extent there are details about copyright that you do not need to worry about, and there will be times when you will need to seek legal advice from a lawyer or legal expert who does understand all the layers and complexities of copyright. However, in the meantime, the basics are much easier to grasp than you might think. And, when it comes to copyright, a little bit of knowledge can go a long way.

Understanding the copyright basics now can help to inform early decisions that avoid bigger problems down the line. It will also give you enough of an understanding to know when it is time to find a legal expert. Moreover, when you do speak to that expert, you will actually know what on earth they are talking about, rather than being totally lost and feeling out of your depth.

This book is primarily written for musicians, artists, producers, performers and those working in the music industry. It aims to give you a basic overview of copyright, how it applies to music and how it works in the music industry, in a way that is easy to understand - so that you will be able to make informed decisions, one of which is knowing when it is time to find a legal expert! (See more details on finding a legal expert in Chapter 7.)

\subsection{It can help your creativity and your business}

Understanding copyright and its role in the music industry is central to understanding the music business and how it works. Moreover, copyright is a law that is based on policy, which means that it is political and can 
- and does - change dramatically and frequently. The changes made in copyright policy will have direct impact on creators, music and the music industry. It is therefore imperative to have a working knowledge of the regulations that affect the big picture of the music industry, and you as someone working within it.

Likewise, if you are engaged at some level in understanding copyright law and its impact on your industry, you can then get involved and participate in discussions around that change. When copyright rules and policy are made, or changed, it is a response to a new technology, or a development in society, and policymakers and lawmakers require information from those on the ground in order to make those decisions in an effective way. All over the world there are organisations and unions that campaign and lobby ${ }^{7}$ for music and artists' rights, conduct research, write responses to government proposals, and engage in all sorts of other initiatives that you can engage with on a deeper level if you understand what copyright is and what it means for yourself and the industry. (More information about these organisations is provided in Chapter 7.)

Equally, understanding copyright can have direct benefits by helping you with your creativity and creative process. This is because knowing more about the difference between taking inspiration and copyright infringement, for example, can help you to better mitigate the risks of infringement (explained in Part III of this book). Moreover, it will enable you to take advantage of, and build on, freely available ideas and works either in the public domain or benefiting from the exceptions under copyright where permission is not needed (see Chapter 5).

Knowing how copyright works can also help you make informed creative and business decisions. This could be, for example, in relation to avoiding infringement claims, by taking steps in advance to enable you to prove your own independent creativity. Copyright knowledge can

I always wondered why it is called 'lobbying the government' when an organisation or group tries to influence law, policy or decisions of government. So, just in case you were also wondering, here is a short side story: I was at the UK Houses of Parliament, stood in the lobby, outside where the members of parliament sit ... and that's literally it! Before the days of email, in order to persuade your MP of your cause, you simply met them in the lobby. Technically, you can still go to the reception desk in the lobby and ask to see your MP, although these days you'd be better off making an appointment. 
also empower you to understand how to maximise the benefit from your music, for example by utilising different licences.

\subsection{It can help you avoid making mistakes}

Understanding copyright can help you avoid making regrettable mistakes. Not in life, but at least in relation to accidentally signing your soul away, or not signing something and losing your investment in a project - a couple of things people tend to want to avoid.

A very common mistake that I have dealt with for clients in music, and in all areas of creativity in fact, is: 'Oh no, we didn't sign a contract because we were friends.' Emphasis on the word were! ( ${ }^{*}$ Lawyers simultaneously facepalm*.) This can, and does, create all kinds of issues later on. To be totally frank, the fact that you are friends, or partners, is even more of a reason to have a contract! Without a contract it is difficult to know where you stand, who owns what or what can be done with the work. Once you know about copyright and all that comes with it, you will see why it is much better to have a written agreement in place (contracts are discussed in Chapter 8).

Another problem for those less versed in copyright jargon is that they might sign something they did not fully understand. If nothing else, please ask an expert to help you with your contracts before signing. It might seem straightforward, but one little misunderstood word can mean the world of difference. For example, the difference between the word 'licence' or 'assignment' of copyright in a contract can be the difference between letting someone use your work for a limited time or giving it to them forever. (Licences are explained in Chapter 9.)

It is easy to make a mistake when it comes to copyright because there are so many misconceptions and common misunderstandings about what it is, what it does and how it works. When I was working on the copyrightuser.org project, I created a Frequently Asked Questions section on the website. I did this by looking at the most commonly asked copyright questions on an internet forum. ${ }^{8}$ What struck me as more interesting than

8 www.copyrightuser.org/faqs/ accessed 6 November 2020. 
the questions asked, however, was not the questions themselves but the answers provided by other users. The reason this was intriguing to me is because, when someone asks a question, they understand that they do not know what the answer is: that is, evidentially, why they ask the question in the first place. On the other hand, when someone voluntarily answers a question on an online forum, they clearly believe that they know the correct answer. However, to my horror and amazement, what I found was that all of the answers - to the hundreds of questions I looked at were either wholly or particularly incorrect. All of them. Hundreds of incorrect answers. Hundreds of people so confidently advocating their misunderstandings about copyright. I used this data to come up with eight common myths about copyright that we turned into myth/reality cards on the copyrightuser.org website. ${ }^{9}$

This is not the only research to have demonstrated the same point. For example, one asked students: 'Do you know what copyright means?' In all, 84 per cent responded yes. The participants who said they knew what copyright was were then asked to explain what copyright means. Again, all of their descriptions were either wholly or partially incorrect. ${ }^{10}$ Likewise, the Kantar Media Online Copyright Infringement Tracker shows annually that awareness and understanding of copyright infringement remains lacking for users. ${ }^{11}$

But! Fear not, because this here book will bust those myths and give you a clear understanding about what copyright is, how it works in the music industry and how to exploit your copyright and enforce it to protect your work.

www.copyrightuser.org/educate/enjoy/myth-reality-cards/ accessed 6 November 2020.

10 Palfrey J, Gasse U, Simun M and Barns RF, 'Youth, Creativity and Copyright in the Digital Age' (2009)

1(2) International Journal of Learning and Media 79.

11 Kantar Media, Online Copyright Infringement Tracker Wave 8 (UK Intellectual Property Office, 2018) 53. 